EGG-FSP--9125

LE91 006206

\title{
GAS RETENTION IN IRRADIATED BERYLLIUM
}

J. M. Beeston, L. G. Miller, G. R. Longhurst Idaho National Engineering Laboratory

and

R. A. Causey

Sandia National Laboratory

June 1990

Idaho National Engineering Laboratory

EG\&G Idaho, Inc.

P.0. Box 1625

Idaho Falls, ID 83415-3523

Work supported by U.S. Department of Energy, Director of Energy Research, Office of Fusion Energy under DOE contract No. DE-ACO7-76ID01570. 
CONTENTS

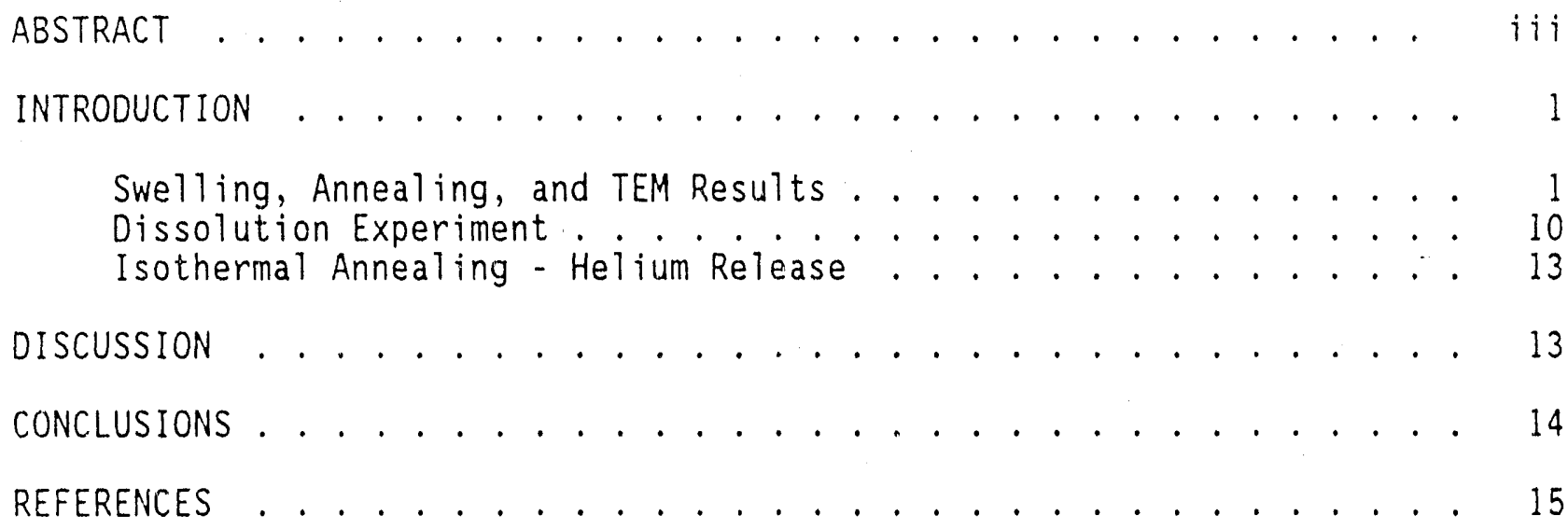




\begin{abstract}
Helium (an inert gas) with low solubility in beryllium is trapped in irradiated beryllium at low temperatures $\left(<100^{\circ} \mathrm{C}\right)$ while the tritium generated may have some mobility and be released. The subject of tritium retention in irradiated beryllium within fusion reactor blankets is of considerable interest in their conceptual design. Results from experiments on three sets of irradiated beryllium specimens are examined in this paper. The beryllium specimens were irradiated at aoout $75^{\circ} \mathrm{C}$ in capsules to protect them from the cooling water. One set of samples was irradiated to $-3 \times 10^{22} \mathrm{n} / \mathrm{cm}^{2} \quad(E>1 \mathrm{MeV})$. In these samples the calculated helium generated was $-14,100$ appm. They are described in terms of swelling, annealing, microstructure, and helium bubble behavior (size, density and mobility). A second sample was irradiated to $\sim 5 \times 10^{22} \mathrm{n} / \mathrm{cm} 2$ (E>1MeV). In that one the calculated helium and tritium generated were $-24,000$ appm $\mathrm{He}$ and $-3,270$ appm, and tritium content was examined in a dissolution experiment. After decay for 8.2 years assuming $100 \%$ retention the tritium content was estimated to be $-2,100$ appm tritium $(-32.6 \mathrm{Ci})$ in $4.7-\mathrm{g}$ samples. The total tritium measured was $32.79 \mathrm{Ci}$. Most of the tritium was released as gas to the glovebox indicating the generated tritium was retained in the helium bubbles. In a third set of experiments a specimen was examined by annealing at a succession of temperatures to more than $600^{\circ} \mathrm{C}$ for tritium release. In the temperature range of $300-500^{\circ} \mathrm{C}$ little release $(0.01-0.4 \%)$ occurred, but there was a massive release at just over $600^{\circ} \mathrm{C}$. The results of these experiments indicate that the tritium tends to collect in the smail helium bubbles which have low mobility at temperatures less than $500^{\circ} \mathrm{C}$. Theories of swelling appear to adequately describe bubble behavior with breakaway release occurring at high helium contents and at large bubble diameters.
\end{abstract}




\section{GAS RETENTION IN IRRADIATED BERYLLIUM}

\section{INTRODUCTION}

Gas retention in nuclear fuels and neutron irradiated metals, especially beryllium, has been of considerable interest for some time. ${ }^{(1-4)}$ Recently, the subject of tritium retention in the beryllium of breeding blankets has been attracting attention in fusion reactor safety analyses. Although much information is available on the behavior of helium in beryllium, little attention has been given to the accompanying tritium in beryllium. Since helium (an inert gas) is considered to have very low solubility in beryllium, while tritium may have appreciable solubility, the question arises as to whether the tritium follows the helium into small bubbles and behaves as does the helium gas.

Results from three sets of irradiated beryllium specimens are examined in this analysis. The beryllium specimens were all irradiated as part of the Advanced Test Reactor (ATR) surveillance program. Samples were nominally $1 \mathrm{~cm}$ in diameter and $3 \mathrm{~cm}$ long with a mass of about $4.7 \mathrm{~g}$.

The beryllium specimens were irradiated in the Experimental Test Reactor (ETR) and ATR in capsules at about $75^{\circ} \mathrm{C}$ to protect them from the cooling water. The $\mathrm{s}^{n}$ lid chemistry of the hot-pressed, beryllium specimens is given in Table I. These specimens had a structure of equiaxed grains with fine oxide particles at the grain boundaries and through the grains. The metallic impurities which exceed the solubility limit are finely dispersed, primarily along grain boundaries. The average grain diameter was about $25 \mu \mathrm{m}$.

\section{SWElling, ANNEALing, and TEM Results}

The first set of experiments to be discussed includes four specimens from which density, annealing at three temperatures, and transmission electron. microscopy (TEM) measurements were obtained. The helium generated during irradiation in the beryllium is highly insoluble and would precipitate as very fine bubbles except that re-solution of the gas (because of displacement) and 
Table 1. Solid Chemistry of Hot-Pressed Beryllium.

\begin{tabular}{ccc}
\hline Element & $\begin{array}{c}\text { Lot } 2811 \\
\text { Content } \%\end{array}$ & $\begin{array}{c}\text { Lot } 2870 \\
\text { Content }\end{array}$ \\
Be & 98.67 & 98.26 \\
Beo & 1.67 & 1.70 \\
$\mathrm{C}$ & 0.110 & 0.100 \\
$\mathrm{AT}$ & 0.100 & 0.085 \\
$\mathrm{Cr}$ & 0.011 & 0.010 \\
$\mathrm{Fe}$ & 0.130 & 0.153 \\
$\mathrm{Mg}$ & 0.004 & 0.006 \\
$\mathrm{Mn}$ & 0.016 & 0.012 \\
$\mathrm{Ni}$ & 0.014 & 0.014 \\
$\mathrm{Cu}$ & 0.009 & 0.008 \\
$\mathrm{Si}$ & 0.030 & 0.030 \\
$\mathrm{Ti}$ & 0.024 & 0.021
\end{tabular}

transmutation reactions keep the structure "stirred up" at this irradiation temperatura $\left(<100^{\circ} \mathrm{C}\right)$. This effect is evidenced by TEM pictures of specimens cut from samples after irradiation (shown in Figure 1). Four irradiated specimens were cut in half; one half was used for the preanneal control for density and TEM, the other half was annealed at temperatures between 200 and $500^{\circ} \mathrm{C}$ for one hour. The results of the density measurements are given in Table 2 and Figure 2. From the electron microscopy (Figures 1 and 3 ) it can be seen that the swelling can be correlated with the resolution of gas bubbles. At temperatures $<100^{\circ} \mathrm{C}$ after irradiation, and after a $200^{\circ} \mathrm{C}$, one-hour annealing, the gas bubbles are not resolved. After annealing at 300,400 , and $500^{\circ} \mathrm{C}$, the gas bubbles are resolved at about 30,60 , and $90 \AA$.

Inasmuch as the tritium may follow the helium into the bubbles, some insight into the probable tritium release behavior can be ascertained from the beryllium swelling, TEM results, and theories of bubble behavior. ${ }^{(1-1)}$ 


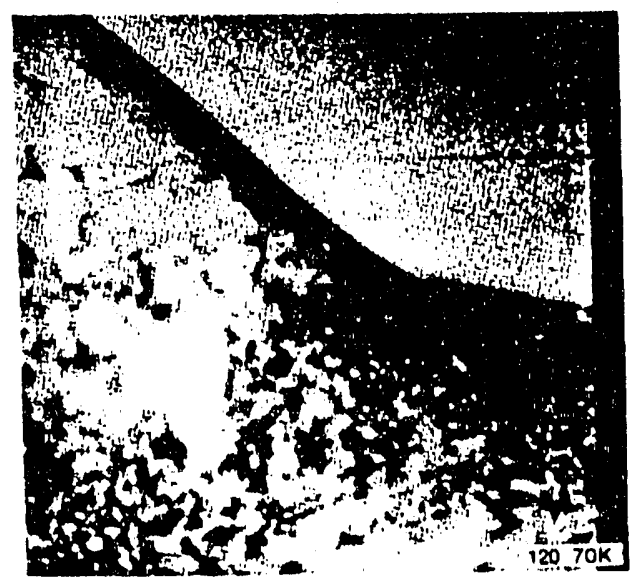

A. Specimen 120 , Fluence of

$3.1 \times 10^{22} \mathrm{n} / \mathrm{cm}^{2}$ at $\mathrm{T}=-100{ }^{\circ} \mathrm{C}$.

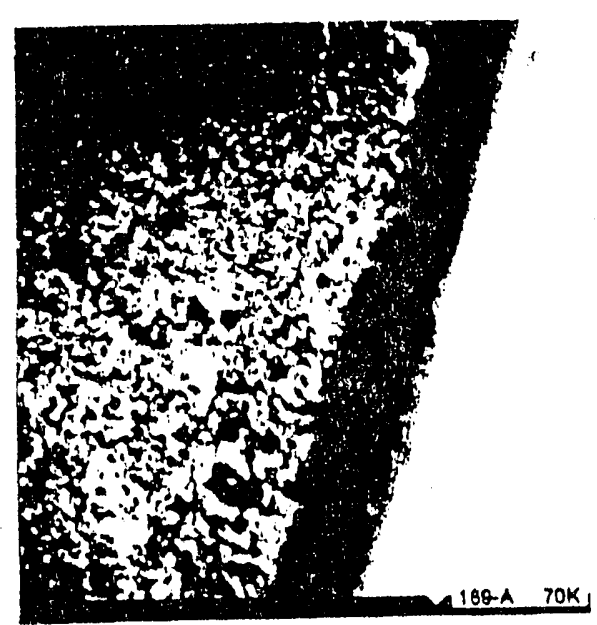

B. Specimen $169-A_{1}$ Fluence of $3.0 \times 10^{22} \mathrm{n} / \mathrm{cm}^{2}$ at $\mathrm{T}=-100^{\circ} \mathrm{C}$.

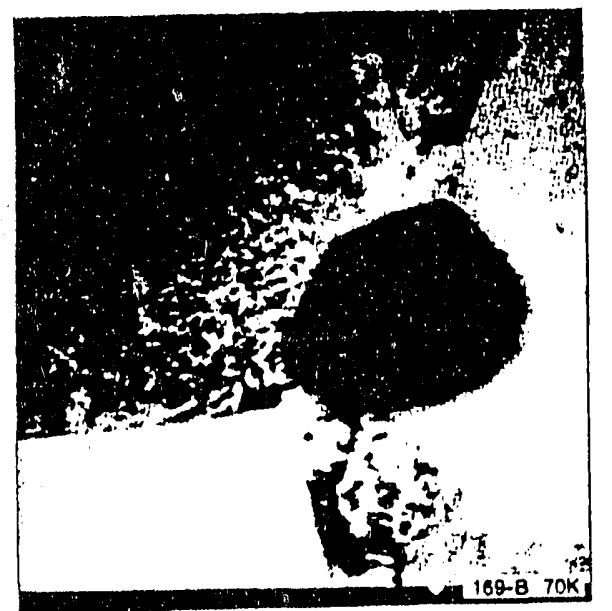

C. Specimen 169-B, Fluence of $3.0 \times 10^{22}$ $\mathrm{n} / \mathrm{cm}^{2}$ at $\mathrm{T}=200^{\circ} \mathrm{C}$ for one hour.

Figure 1. Bubbles not resolved.

Assuming uniform bubble size, the number of bubbles $/ \mathrm{cm}^{3}, \eta$, can be calculated from the swelling. Beginning with the $\Delta \rho / \rho(\%)$ values given in Table 2 , the change in specific volume is given by 


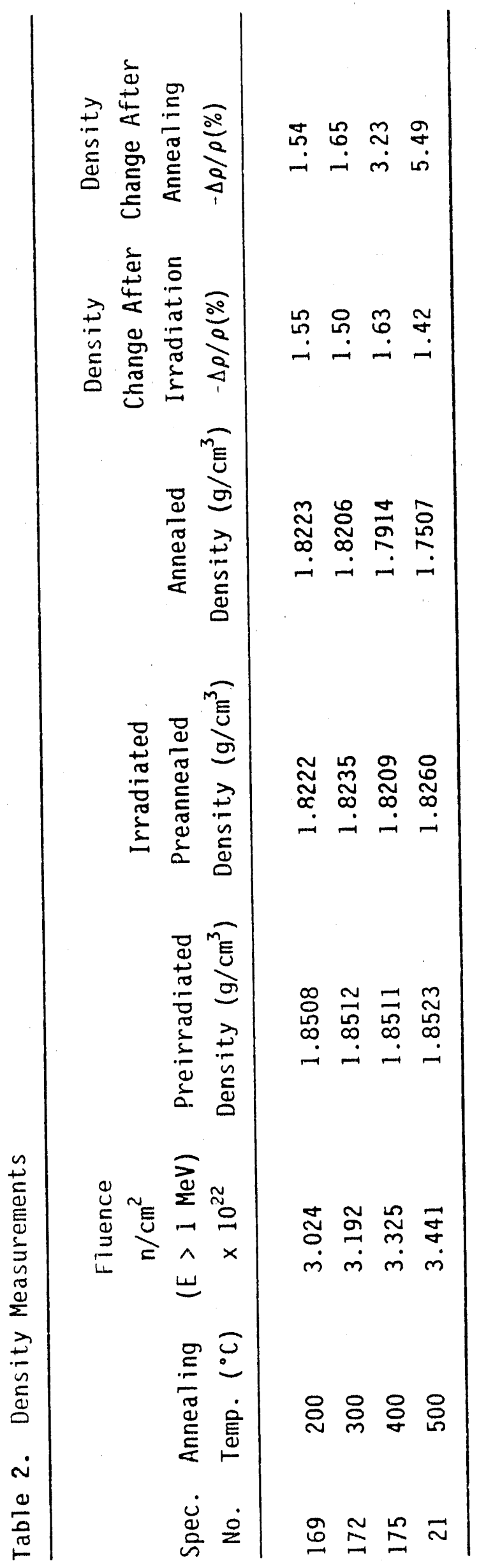




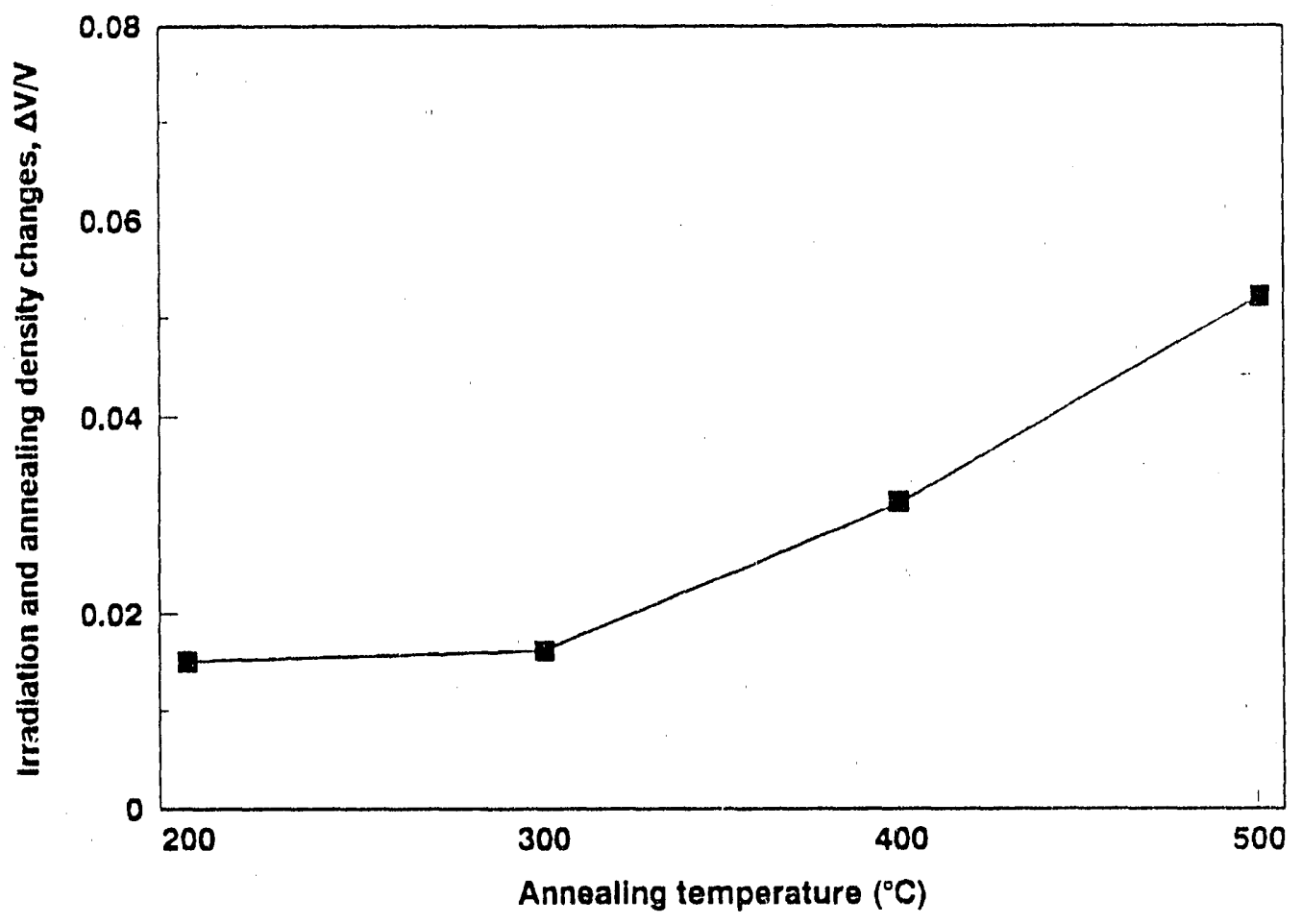

Figure 2. Irradiation and annealing density change.

$$
\frac{\Delta V}{V}=\frac{-\frac{\Delta \rho}{\rho}(\%)}{100+\frac{\Delta \rho}{\rho}(\%)}
$$

and then

$$
\eta=\frac{3 \frac{\Delta V}{V}}{4 \pi r^{3}} \quad\left(\frac{\text { bubbles }}{\mathrm{cm}}\right) \text {. }
$$

$\eta$ is calculated using the radii from Figure 3 for the samples annealed at 300 , 400 , and $500^{\circ} \mathrm{C}$, as $1.5 \times 10^{17}, 3.7 \times 10^{16}$, and $1.9 \times 10^{16}$ bubbles $/ \mathrm{cm}^{3}$, respectively. The partial pressure of He in these bubbles can be estimated from the number of He atoms assumed to be in the bubbles and the temperature. It is given by 


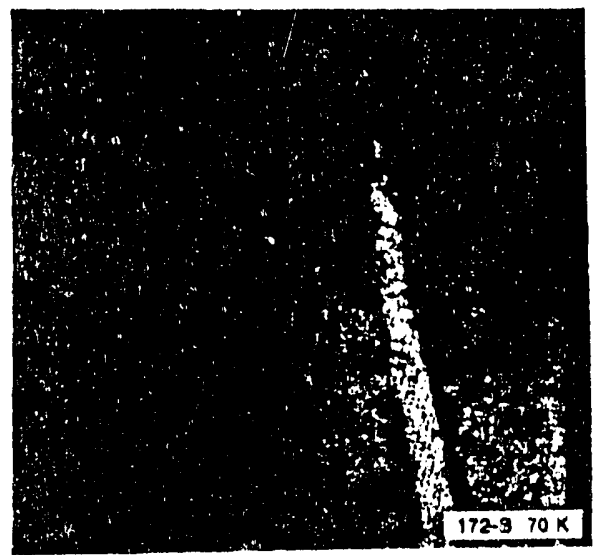

A. Specimen $172-8$, fluence of $3.2 \times 10^{22} \mathrm{n} / \mathrm{cm}^{2}$ at $T=300^{\circ} \mathrm{C}$ for one hour. 8ubbles about 30 Angstroms diameter.

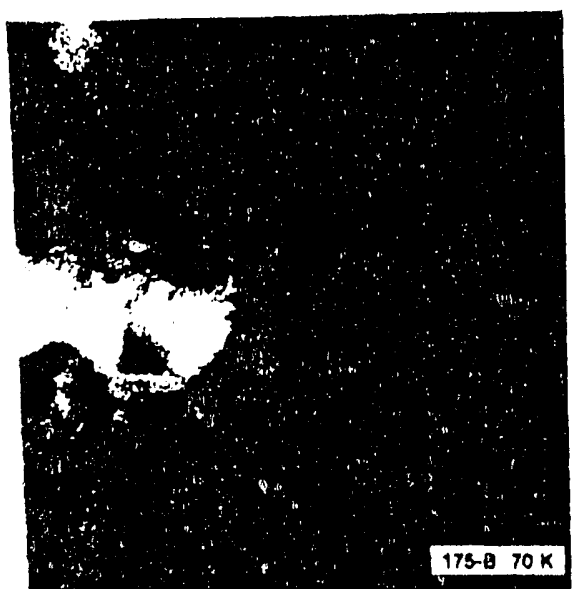

8. Specimen $175-8$, Fluence of $3.3 \times 10^{22}$ $\mathrm{n} / \mathrm{Cm}^{2}$ at $\mathrm{T}=400^{\circ} \mathrm{C}$ for one hour. Bubbles about $60 \mathrm{~A}$ diameter.

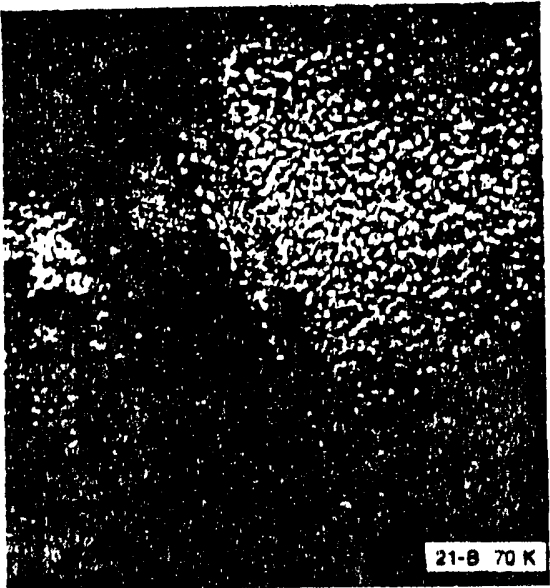

C. Specimen 21 , Fluence of $3.4 \times \mathrm{jO}^{22}$ $\mathrm{n} / \mathrm{cm}^{2}$ at $T=500{ }^{\circ} \mathrm{C}$. Bubbles about $90 \mathrm{~A}$ diameter.

Figure 3. Bubbles resolved after annealing at the temperatures indicated.

$$
P_{\mathrm{He}}=\frac{n_{g} V}{\Delta V} k T
$$

where $n_{g}$ is the number of He atoms generated per cubic meter based on neutron cross sections and fluence. Assuming a generation rate of 0.0047 atoms $\mathrm{He} / \mathrm{atom}$ $\mathrm{Be} / 10^{2 i} \mathrm{n} / \mathrm{cm}^{2}$ ( $\left.E>1 \mathrm{MeV}\right), \mathrm{n}_{\mathrm{g}}$ is estimated to be $1.86 \times 10^{27}, 1.94 \times 10^{27}$, and $2.00 \times 10^{27}$ atom He$/ \mathrm{m}^{3}$ Be for the specimens at 300,400 , and $500^{\circ} \mathrm{C}$, respectively. Using the ideal gas 1 aw, partial pressures are calculated to be 875,540 , and 369 
$\mathrm{MPa}$, respectively. These values suggest the ideal gas la'v only applies poorly as will be indicated later.

The radi $i$ estimated based on the TEM immages of Figure $3(30,60$, and $90 \AA$ ) may be compared with those calculated using the perfect gas 1 aw and the relationship:

$$
r=\frac{2 \gamma \frac{\Delta V}{V}}{n_{g} k T}
$$

where:

$$
\begin{aligned}
& n_{g}=\text { number of gas atoms } / \mathrm{m}^{3} \\
& \gamma=\text { surface energy }\left(-\mathrm{J} / \mathrm{m}^{2}\right),
\end{aligned}
$$

Values so calculated were 23,37 , and $54 \AA$, in reasonable agreement with those estimated from TEM.

The bubbles will migrate because of the annealing temperature gradient $(d T / d x)$, and the velocity of the bubbles will depend on the surface and volume diffusion coefficients, ${ }^{(3)}$ as well as the concentration gradients. The selfdiffusion coefficient for beryllium, ${ }^{(5)}$

$$
D=5.2 \times 10^{-5} \exp \left[-\frac{13922}{T(K)}\right]\left(\frac{m^{2}}{s}\right),
$$

is small $\left(<2 \times 10^{-14} \mathrm{~m}^{2} / \mathrm{s}\right)$ at these temperatures $\left(200-600^{\circ} \mathrm{C}\right)$, and since helium (an inert gas) is practically insoluble in beryllium, the diffusion coefficient for tritium will be used to estimate the bubble mobility. The diffusion coefficient for tritium in beryllium given by Jones and Gibson ${ }^{(6)}$ is: 


$$
D=3 \times 10^{-11} \exp \left[-\frac{2222.4}{T(K)}\right]\left(\frac{m^{2}}{s}\right) \text {. }
$$

This coefficient will be used in the equation to estimate the velocity of the bubbles $\left(V_{s}\right)$, from which the distance the bubbles travel during a one-hour annealing can be calculated:

$$
V_{s}=\frac{36}{\pi^{2}} \frac{\Omega^{1 / 3}}{r} \frac{D}{T} \frac{d T}{d x}
$$

where:

$$
\begin{aligned}
& \Omega=\text { atomic volume of } \mathrm{Be}\left(8.11 \times 10^{-30} \mathrm{~m}^{3} /\right. \text { atom) } \\
& \frac{d T}{d x}=100^{\circ} \mathrm{C} / \mathrm{m} \text { (calculated by thermal analysis for specimens } \\
& \text { placed in a furnace for one hour annealings) }
\end{aligned}
$$

As shown in Figure 4 , the bubble diameter at $600^{\circ} \mathrm{C}$ is obtained from an extrapolation. The calculation for $V_{s}$ at $300,400,500$, and $600^{\circ} \mathrm{C}$ gives $5.28 \times 10^{-14}, 4.02 \times 10^{-14}, 3.56 \times 10^{-14}, 3.28 \times 10^{-14} \mathrm{~m} / \mathrm{s}$, respectively, and gives a total distance of $5.8 \times 10^{-10} \mathrm{~m}$ for one-hour annealings. Since the grain diameter is approximately $25 \mathrm{\mu m}$, the fraction of the grain diameter travelled in the one-hour annealings is $2.4 \times 10^{-5}$. Thus, the bubbles travel a very short distance in the grains for the one-hour annealings.

If the bubbles are randomily oriented within the grain, they will touch each other and the gas will be released ${ }^{(3)}$ when the radius ( $r$ ) is given by:

$$
r=\frac{2 \gamma}{3 k T n_{g}}
$$

where:

$$
n_{g}=\text { the number of gas atoms } / \mathrm{m}^{3} \text { in the grain }\left(-2 \times 10^{27} \text { atoms } / \mathrm{m}^{3}\right) \text {. }
$$

Thus, at $500^{\circ} \mathrm{C}$, the effective bubble radius may be estimated as 


$$
r=\frac{2}{3\left(1.38 \times 10^{-23}\right)(773)\left(2 \times 10^{27}\right)}-312 \mathrm{~A}
$$

The behavior of the helium (and trapped tritium) for the set of annealed specimens has been described in terms of theories of swelling and gas retention. The calculations for annealing up to $500^{\circ} \mathrm{C}$, using the perfect gas law, indicate that the bubbles need to grow larger before "breakaway" release of the gas occurs (the swelling at which a large number of bubbles touch, releasing their gas content). For the specimens irradiated to $3 \times 10^{22} \mathrm{n} / \mathrm{cm}^{2}$ (gas content of $2 \times 10^{21}$ atom $\mathrm{He} / \mathrm{cm}^{3}$ beryllium), a radius of 312 A was indicated as needed for gas release. However, since tritium is not insoluble in beryllium, as is the inert gas helium, it may be that some tritium would be released at temperatures less than $500^{\circ} \mathrm{C}$. There is a 1 imit to the amount of gas which can be contained within

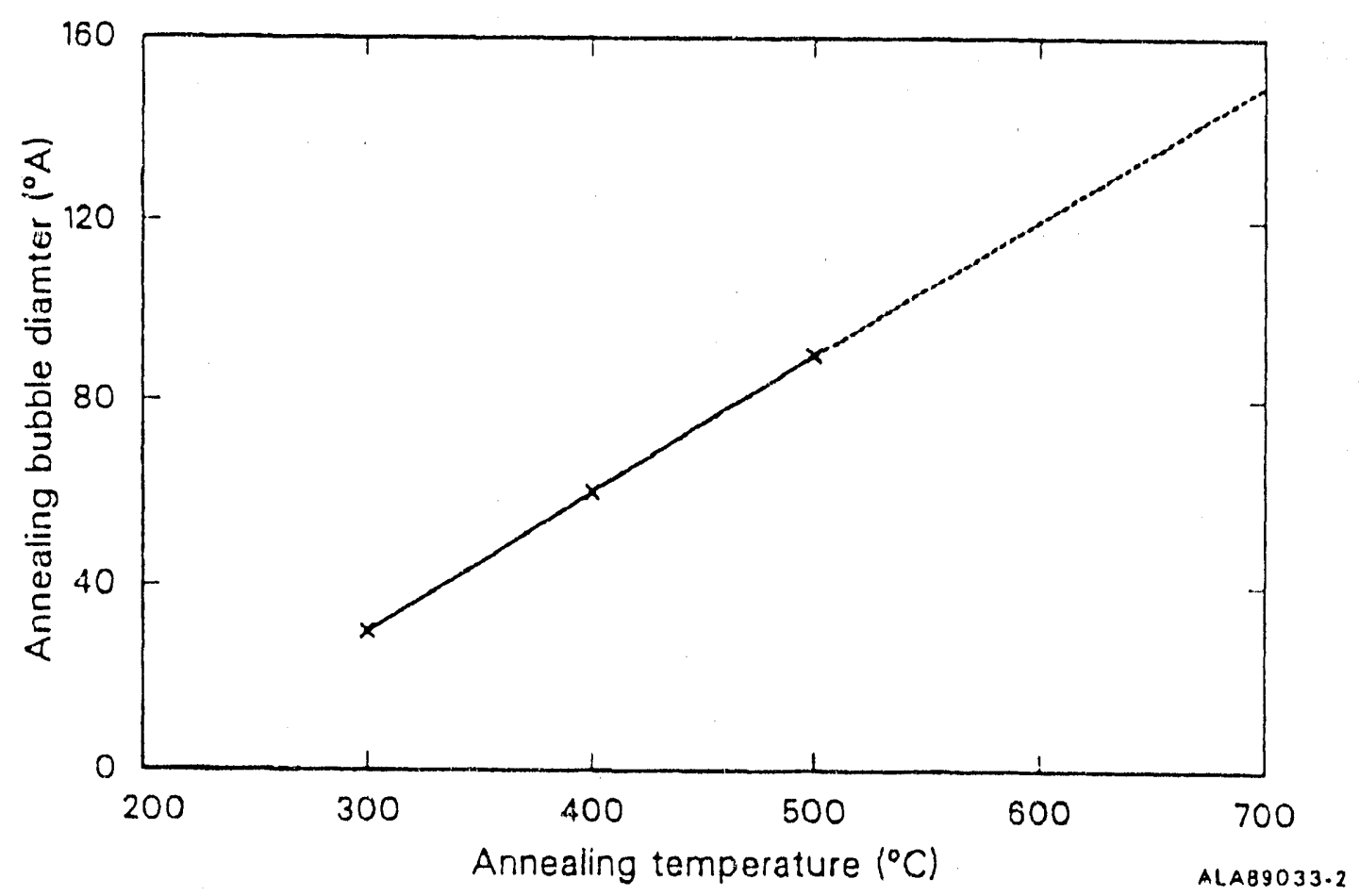

Figure 4. Annealing bubble diameter vs temperature. 
the grains. At the small bubble radius a better gas law (Van der Waal's) has been used. Barres and Ne? son ${ }^{(3)}$ have made this correction using van der Waal's law and have shown the concentration limit for "breakaway" swelling, at the small bubble radii, to be at approximately $3 \times 10^{27}$ gas atoms $/ \mathrm{m}^{3}$ (Figure 5 ). The maximum amount of gas that can be contained within the grains (mg) is plotted as a function of radius for $500^{\circ} \mathrm{C}$ and $1,750^{\circ} \mathrm{C}$. Thus, as indicated in Figure 5 , "breakaway" swelling would be expected for specimens irradiated to $5 \times 10^{22} \mathrm{n} / \mathrm{cm}^{2}$ $(E>I \mathrm{MeV}),\left(-3 \times 10^{27}\right.$ atoms $\left.\mathrm{He} / \mathrm{m}^{3} \mathrm{Be}\right)$ at temperatures of $600^{\circ} \mathrm{C}$.

\section{DISSOLUTION EXPERIMENT}

The second set of experiments discussed utilized one specimen that had been irradiated to a fluence of $5 \times 20^{22} \mathrm{n} / \mathrm{cm}^{2}$ (E>1 MeV). The specimen was examined at Sandia Nationai Laboratory, Livermore. Th te beryllium specimen, with the same composition as the samples in the first set of experiments discussed and original Jimensions of $1.02 \mathrm{~cm}$ diameter $\times 3.12 \mathrm{~cm}$ long with a mass of $4.70 \mathrm{~g}$, had been iriadiated to high fluence with resulting calculated nigh helium and tritium contents $\left(-24,000 \mathrm{appm}\right.$ He or $3 \times 10^{21}$ atoms $\mathrm{He} / \mathrm{cm}^{3},-3,670$ appm tritium). This specimen was analyzed for tritium in a dissolution experiment. Since it had been decaying for 8.2 years before being analyzed, the tritium content, assuming $100 \%$ retention, was expected to be $\sim 2,100$ appm tritium $(-32.6 \mathrm{Ci})$.

The dissolution experiment was performed in a glovebox located in the Tritiun Research Liboratory of Sandia National Laboratories in Livermore, CA. The sample was dissolved in a series of four steps using $100 \mathrm{~mL}$ of 3 -molar sul. uric acid in each step. The process time for each dissolution was approximately 10 minutes. After the dissolution was completed, $25 \mathrm{~mL}$ samples of each etch solution were collected for scintillation counting. This produced scintillation samples with a tritium signal too intense for counting. These samples were jiluted by a factor of 20 to obtain samples that could be counted without serious deadtime losses on the detector. While the beryllium sample was being dissolveu, an ionization detector inside the glovebox measured the amount of tritium not being coilected in the acid solutions. The glovebox was isolated during the operation. Results are shown in Tabie 3. 


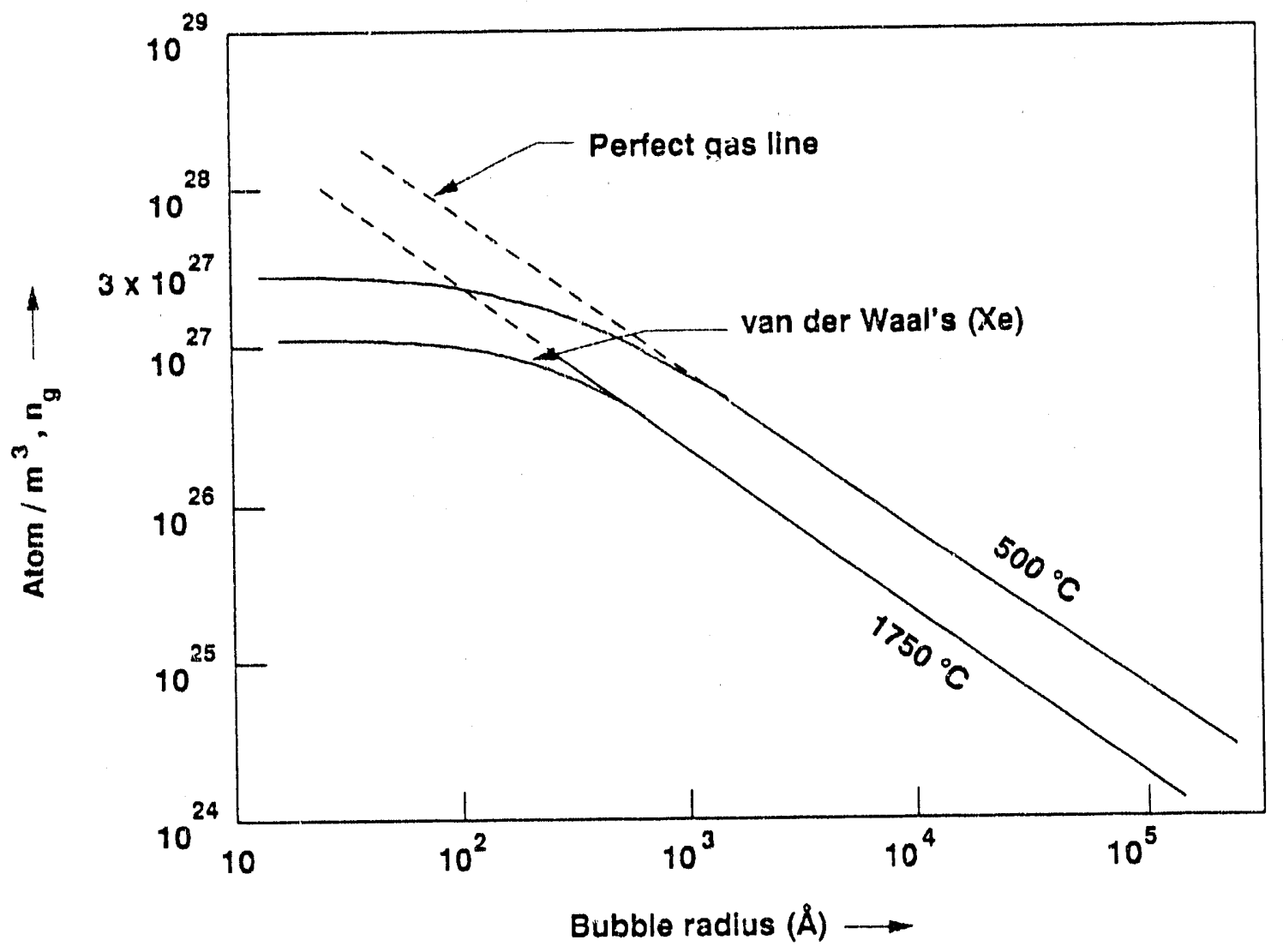

Figure 5. Breakaway Swelling. The maximum amount of gas which can be contained within the grains $\left(n_{g}\right)$ as a function of radius for $500^{\circ} \mathrm{C}$ and $1750^{\circ} \mathrm{C}$.

There was a small decrease in tritium concentration as the layers were removed. Concentrations were measured at approximately $7.3 \mathrm{Ci} / \mathrm{g}$ at the outside of the sample and about $6.2 \mathrm{ci} / \mathrm{g}$ near the center. The most surprising result of the experiment was the failure of the acid solution to capture the released tritium. Typically, when tritium containing materials are dissolved in acid solutions, the tritium isotopically exchanges with hydrogen in the solution and is retained. This did not happen in this experiment. One possible explanation is that the tritium in the beryllium was in the form of tritium molecules (tritium and helium in the bubbles). 
Table 2. Tritium Dissolution Experiment Results.

$\begin{array}{ccc}\begin{array}{c}\text { Amount of Sample } \\ \text { Removed (g) }\end{array} & \frac{I \text { in Acid (Ci) }}{0.22} & \frac{I \text { in Glovebox (Ci) }}{9.8} \\ 1.35 & 0.20 & 7.8 \\ 0.85 & 0.15 & 5.4 \\ 1.45 & \underline{0.22} & \frac{9.0}{32.0}\end{array}$

It should also be noted that the dissolved beryllium specimen aparently contained nearly all the tritium generated (minus that which decayed). Diffusion of tritium from the beryllium at temperatures less than $100^{\circ} \mathrm{C}$ is minimal. The experimental results suggest tritium follows the helium into small bubbles. As shown in Figure 1 (TEM photographs for the other specimens), the bubbles could have been present, but not resolved because of the tangled structure from irradiation. At temperatures sufficient to anneal the irradiation damage (interstitial beryllium atoms), the bubbles became resolved (as shown in the TEM photographs!.

\section{Isothermal ANNEALIng - HeLIUm Release}

The third set of experiments involved irradiated specimens sent to Dr. David Baldwin (7) at Battelle Nortinest for tritium release measurements. These specimens were also of the same composition. They, too, were irradiated to $5 \times 10^{22} \mathrm{n} / \mathrm{cm}^{2}$ ( $E>1 \mathrm{MeV}$ ) and contained 24,000 - 30,000 appm Helium. It is sufficient for the present purpose to state that Dr. Baldwin's experiment consisted of heating a sample in stages $\left(300,411,511\right.$, and $\left.611^{\circ} \mathrm{C}\right)$. There was modest release of tritium at the lower temperatures, but a massive release of the tritium was observed at $611^{\circ} \mathrm{C}$. 


\section{DISCUSSION}

Billone ${ }^{(8)}$ has reviewed Baiwin's data and indicated that the recent tritium release data from irradiated $\mathrm{Be}$ in the temperature range of $300-500^{\circ} \mathrm{C}$ gives little (0.01-0.4\%) release; however, a massive release occurs at approximately $600^{\circ} \mathrm{C}$. Within the assumptions in the calculations, we have shown that upon annealing, helium in beryllium and, presumably, tritium does produce bubble sizes as theories ${ }^{(1-4)}$ would indicate in the $300-500^{\circ} \mathrm{C}$ temperature range. The helium (Figures 1 and 3 ) and tritium (as shown in the dissolution experiment) did seem to be retained as if in bubbles. The bubbles gave the appearance of slow growth as a function of annealing temperature, even at temperatures of $300-500^{\circ} \mathrm{C}$. However, in annealing tests at those temperatures, the distance traversed was less than a gral:: diameter, even after 100 hours. The bubbles may have been affected by pinning from oxide and impurity particles, and the temperature gradients certainly did not persist for 100 hours during annealing tests.

There will be some re-solution of the gas during irradiation because of displacement and transmutation reactions. Figure 6 (taken from $B i l l o n e^{(3)}$ ) depicts the fraction of "trapped" hydrogen isotope in Be as a function of annealing temperature's. Billone showed (Figure 6) an apparent anomaly between 500 and $600^{\circ} \mathrm{C}$ in the tritium release for the irradiated beryllium; however, the helium content of the specimens irradiated to $5 \times 10^{22} \mathrm{n} / \mathrm{cm}^{2}$ (gas content of $3 \times 10^{27}$ atoms $/ \mathrm{m}^{3}$ ) was at the 1 imit for breakaway release of the helium, even at the small bubble diameter of $120 \AA$ (Figure 5). The anomaly was apparently due to the breakaway release of helium.

\section{CONCLUSIONS}

Most of the tritium in irradiated beryllium evidently follows the helium into small bubbles at irradiation temperatures of $<100^{\circ} \mathrm{C}$ and stays in the bubbles for a long time ( $>8.2$ years). 


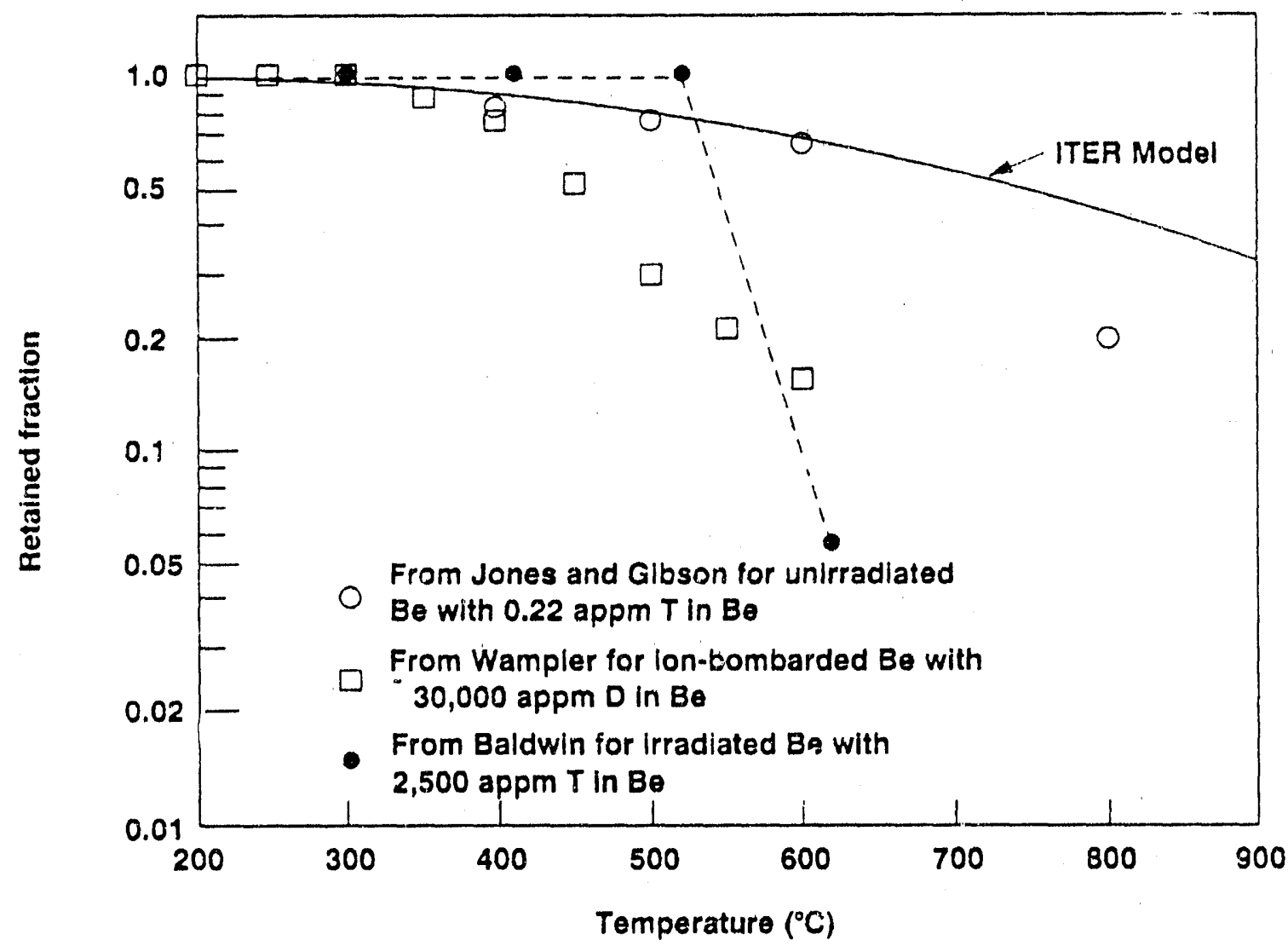

Figure 6. Breakaway sivelling. The maximum amount of gas which can be contained within the grams (mg) plotted as a function of radius for 500 and $1750{ }^{\circ} \mathrm{C}$.

The behavior of the bubbles containing the helium and tritium in annealing experiments can be described in terms of the theories of bubble behavior.

The massive release of helium and tritium that occurs at $600^{\circ} \mathrm{C}$ can be described in terms of breakaway release of the gas in bubbles that occurs because of the limit of gas content in the beryllium structure at high gas contents.

Release of helium from irradiated beryllium at gas concentrations less than the breakaway limit may occur in accordance with theories of swelling and gas retention. The tritium release apparently follows the helium at intermediate temperatures. 


\section{REFERENCES}

1. C. E. E11s and E. C.W. Perryman, "Effects of Neutron-Induced Gas Formation on Beryllium," J. NuCl. Matl. 1: 73-84 (1959).

2. R. S. Barnes, "A Theory of Swelling and Gas Release For Reactor Materials," J. NuCl. Mat1. 11: 135-148 (1964).

3. R. S. Barnes and R. S. Nelson, "Theories of Swelling and Gas Retention in Reactor Materials, "Metallurgical Society Conferences, AsheviTle, NC, 225-267 (September 1965).

4. E. E. Gruber, "Analysis of the Effect of an Energy Gradient on Bubble Coalescence in Solids," Metallurgical Society Conferences, Asheville, NC, 269-274 (September 1965).

5. N. L. Peterson, "Self-Diffusion in Pure Metals," J. Nucl. Mat7. 69-70: $3-37(1978)$.

6. P. M. S. Jones and R. Gibson, "Hydrogen in Beryllium," J. Nucl. Matl. 21: $353-354$ (1967).

7. D. L. Baldwin, INEL Beryllium Workshop, September 11, 1989, to be published in J. NuCl. Matl.

8. M. C. Billone letter to C. C. Baker, Argonne National Laboratory, September 25, 1989. 

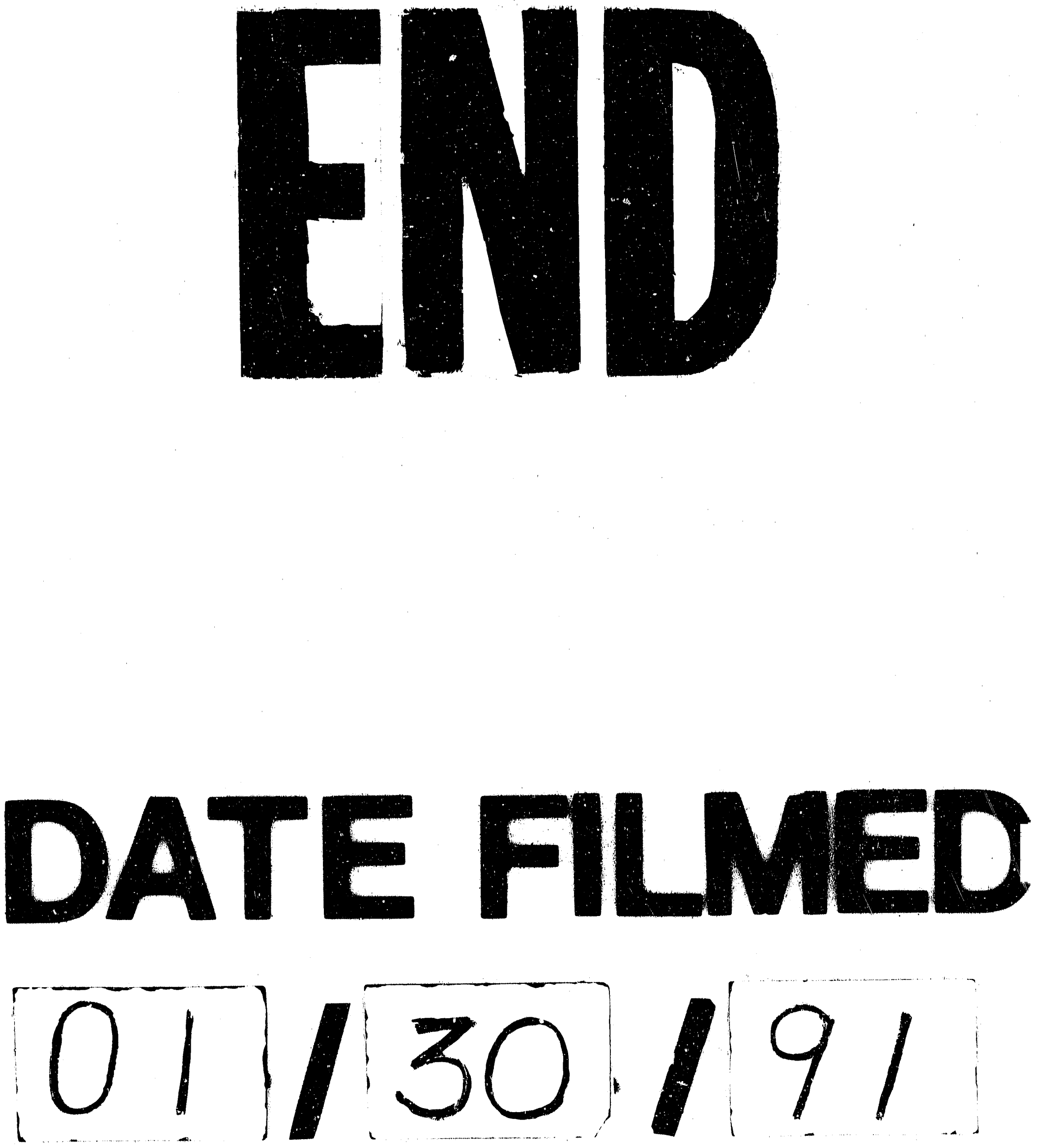


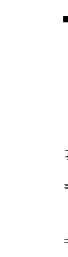

